\title{
The Effects of De-energizing Ties in Organizations and How to Manage Them
}

\author{
ANDREW PARKER \\ Grenoble Ecole de Management \\ 12 rue Pierre Sémard \\ Grenoble 38000 , France \\ $+3347670 \quad 6595$ \\ andrew.parkerdgrenoble-em.com
}

\author{
ALEXANDRA GERBASI \\ Grenoble Ecole de Management \\ 12 rue Pierre Sémard \\ Grenoble 38000 , France \\ $+3345680 \quad 6614$
}

alexandra.gerbasi@grenoble-em.com

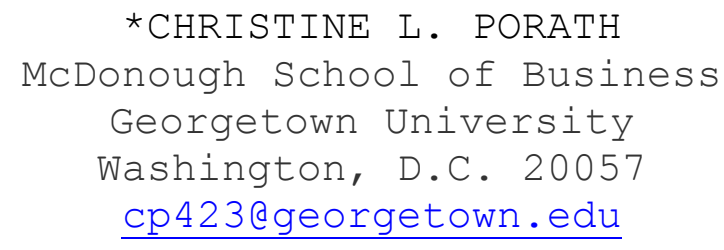

*Indicates corresponding author.

Accepted at Organizational Dynamics (November 2012) 


\section{Executive Summary}

While there is growing recognition about the role of informal networks in organizations and the importance of energizers in the workplace, chances are that managers and organizations are missing a potentially devastating expense: deenergizers. Over the past decade $w e^{\prime}$ ve studied the effects of negative or de-energizing ties, defined as enduring, recurring set of negative judgments, feelings, and behavioral intentions towards another person. While de-energizing ties may represent a relatively small proportion of ties, they have a disproportionately potent effect on individuals, other employees, and teams within organizations. At the individual level de-energizing relationships can result in blocked opportunities, decreased motivation, and even organizational isolation. The consequences include decreased levels of thriving, lower performance, and increased likelihood of exit. The effects on others are very similar. Countless co-workers often get sucked into these negative situations. At the team level de-energizing ties can cause more conflict, lower team cohesion and trust, and decrease boundary spanning activity. The result is less access to critical information, a decrease in the ability to solve problems, and overall lower team performance. De-energizing ties are not insurmountable, though. Managerial actions, such as conflict resolution, training and 
mentoring, as well as staffing changes, can change the dynamics of informal organizational networks and minimize the effects of de-energizing ties. Likewise, individual actions such as better awareness and strategic management of one's own network can decrease the effects of de-energizing relationships. In this article we detail these and other recommendations for leaders and individuals to manage the effects of de-energizing ties. 


\section{The Effects of De-energizing Ties in Organizations and How to Manage Them}

Ask people about who they have worked with and most will recount stories of those that have motivated them, those that have made them laugh, and those that they have shared good times with. Dig a little deeper and stories might be told about those colleagues that have brought an individual close to tears or to rage due to their anger at and frustration with a particular person. For example, Mike an Executive Vice President at an entertainment company told us about his experience handling several layoffs with a General Manager. As this V.P. broke the difficult news to this G.M.'s loyal employee, the G.M. sat with his feet perched up on the conference table, working away on his computer. He didn't bother to look up from his computer screen, much less thank his direct report, or express his sympathy. The V.P. recounted that he was particularly upset as he had gone to great lengths to try to coach the G.M. on leadership skills, after sensing employees' frustrations with him. The V.P. indicated that he left the room feeling particularly deenergized by the whole encounter. There were also longer lasting effects for the G.M.: a number of negative interactions similar to this one pushed the V.P. to let him go several months later.

WHAT ARE NEGATIVE TIES AND HOW BIG OF A PROBLEM ARE THEY? 
We all have differences with people in the workplace. Conflict and disagreement are an everyday part of work. While some disagreements are short lived, others are longer lasting. It is on these more enduring negative ties that we focus. Labianca and Brass define them as "enduring, recurring set of negative judgments, feelings, and behavioral intentions towards another person - one person dislikes another." Another way of conceptualizing negative ties is that they are the ones we find de-motivating or de-energizing. There is growing recognition about the important role of informal networks in organizations and the importance of being connected to energizers in the workplace. For example, research indicates that interaction with an energizer results in mutual resource creation, higher performance and emotional attachment. Negative or de-energizing ties are exactly the opposite, they literally draw the life out of an individual's desire to accomplish tasks within an organization and create a need for emotional distance with the de-energizer.

While we can all recognize negative relationships in the workplace, how prevalent are they? Evidence suggests that there are many more instances of positive ties than negative ties. Labianca and Brass suggest that only one to eight percent of relationships within organizations are negative. In over 20 studies in which we have specifically looked at energy within 
social networks, the average percentage of de-energizing ties is seven percent.

While de-energizing ties may represent a relatively small proportion of ties, they have a disproportionately potent effect on people. Consider your own work experiences for a moment: what do you think most about on the commute home? The energizing or the de-energizing interactions? We have interviewed hundreds of people in organizations and it is always the de-energizing interactions that people remember most. Which type of interactions prompt you to seek out colleagues, friends and family members? Again, it is the de-energizing interactions. Our research indicates that a de-energizing interaction with a colleague has between four and seven times the influence of an energizing interaction. While there may be fewer negative influences than positive ones, the effect of de-energizing ties is considerably greater.

In this article, we highlight the losses associated with de-energizing ties based on ten years of research. We discuss the varied ways de-energizing interactions decrease individual and team performance. We review how organizations lose their most valuable assets as employees often choose to exit because of de-energizing relationships at work. We also consider how coworkers get sucked into the fray, further draining resources 
from the organization. Then we share recommendations for what leaders and individuals should do to manage these effects.

\section{Examples of De-energizing Ties in the Workplace}

To illustrate how de-energizing ties in the workplace may play out, we share two typical examples. First, there is the case of Jack who was a longstanding member of an IT team in a global engineering firm. We surveyed the IT department annually for six years. For the first five years, Jack was considered an exemplary colleague. Many saw him as an energizer and a go-to person for information. When we revisited the organization a year later, we found that over half of his colleagues viewed him as a neutral influence at best and a de-energizing influence at worst. Shortly thereafter, Jack left the organization. We talked with his manager and colleagues and found out that Jack had lost interest in his job. His overall level of engagement with the IT department and the organization as a whole had plummeted.

Several employees that relied upon him also saw a drop in their performance and job satisfaction.

Second, consider the case of Paul, an engineer in a large oil and gas organization. Six months prior to our visit to the organization, Paul was promoted to a supervisory position. It was his first management position. In his previous role he was a well-respected engineer, helping solve drilling equipment installation and maintenance issues around the globe. In his new 
role he coordinated the work of 12 engineers scattered across various countries throughout the world. Our survey of the larger group revealed that rather than Paul being a motivating force, he was seen as a source of de-motivation by the members of his team and others within the drilling community. In discussions with several managers and people Paul worked closely with we discovered that he was unable to unite his team and seemed increasingly frustrated. It became apparent that while Paul was an excellent engineer, his lack of managerial experience contributed to his inability to coordinate and unify his team. Unlike in Jack's case, Paul was given team leadership training and assigned a mentor. When we returned to do follow up interviews six-months later, people saw Paul as an energizing motivator and it showed- his team was successfully hitting its goals.

These two examples have important things in common. First, people considered to be de-energizers by their colleagues have not always been that way. In Jack's case, his loss of interest in his position colored his mood and actions. For Paul, it was finding himself in a position for which he did not have the skills and experience. Second, the negative effects were not confined; there were detrimental effects on the work performances and job satisfaction of those around them. These two examples also highlight just how much outcomes can differ. 
The primary difference between the two examples is timely management action. In the case of Paul, management intervened quickly; a valuable employee received some additional training and guidance and the situation was resolved. In the case of Jack, his manager was not aware of the issue, or did not act upon it until it was too late.

The consequences of de-energizing relationships depend on how the manager and individual handle them. The key is: do they recognize them? And then, what do they do to change the course of de-energizing ties and the negative spiral(s) that can ensue? It's crucial that employees and managers recognize and deal with de-energizing relationships as swiftly as possible to minimize these consequences.

\section{THE ROLE OF DE-ENERGIZING TIES IN INFORMAL SOCIAL NETWORKS}

Before discussing the negative side of social networks, we briefly summarize the positive aspects. Considerable research over the last two decades has focused on the benefits of informal social networks in the workplace. Social networks provide valuable knowledge and information that help people better complete work-related tasks. Networks are conduits for ideas that tend to increase innovation within organizations. Social networks are not only beneficial from an instrumental perspective; they also have a range of important affective 
benefits, providing friendship, support and motivation within the workplace. We have found that positive informal ties lead to increased individual and group performance, as well as higher thriving, defined as the joint experience of vitality (feeling energized and alive) and learning (feeling that one is continually improving and getting better at one's work), job satisfaction, and organizational commitment.

Social networks can be envisioned in three ways: (1) as the relationship between any two people, (2) as the number of relationships or ties an individual has, or (3) as the overall structure of the informal network (which includes multiple people and their ties). Research by Rob Cross indicates that individuals often play important roles within informal networks, such as being a broker or an energizer. Although the majority of recent research has focused on networks as positive sources of social support, information and organizational change, our stories earlier in this article highlight the negative potential of social networks. Consider the network diagram in Figure 1. All things being equal, the de-energizing tie between Alan and Beth (bottom left) will disadvantage them both compared to the energizing tie between Colin and Frank (top right). In the energizing tie, information, problem solving advice and support are more likely to flow. Whereas, in the de-energizing tie it is much less likely that information will be shared or if there is, 
it will tend to be more superficial. In addition, there is emotional animosity between Alan and Beth. This situation is made even worse if people have de-energizing ties to those with greater influence in the organization, such as one's boss. <Insert Figure 1 about here>

If we consider another pair of people, Helen and Gayle, we see a de-energizing relationship in one direction (the line between Helen and Gayle has an arrow pointing from Helen to Gayle, but not vice-versa). In this case, Helen indicates that she has a de-energizing relationship with Gayle. This asymmetrical relationship has different implications than the symmetrical one between Alan and Beth. In this case, while Gayle might not have a negative emotional view of Helen, the fact that Helen views the tie as being de-energizing will limit her willingness to share rich information and ideas with Gayle. Ultimately, both parties lose out compared to the energizing tie between Colin and Frank.

In the next example, we move from examining a tie between two people, to focus on particular individuals in the network. If we compare Diane and Edward in Figure 1, we can see that Edward has many more outgoing de-energizing ties compared to Diane. Edward perceives six people in the network as deenergizing. Again, all things being equal, people with more outgoing de-energizing ties will be at a disadvantage because 
they perceive negativity all around them and will gain little emotional support from their network. It's also important to consider how people can buffer the effect of de-energizing ties. While Edward has no energizing ties to buffer the effects of his de-energizing ties, Diane has four energizing ties which will likely mitigate some of the effects of her de-energizing tie. At least when Diane has a de-energizing interaction she can rely on Colin, Frank, Gayle, and Karen to revitalize her.

A slightly different situation occurs when an individual, such as Ian in Figure 1, has many incoming de-energizing ties. This is an indication that numerous people in the network feel that Ian is a de-motivator or maybe is not to be trusted. People are unlikely to pass on useful information to Ian and they will resist having him on their task or team.

Now, let's take a look at how a single de-energizing tie can have a huge impact on many individuals. In Figure 2, the ties within the two groups are all energizing, however the link between them is a de-energizing tie. While each group will benefit from the sharing of information by its group members, the de-energizing tie between the two groups likely limits the information benefits that can be obtained from the other group. In this scenario, just one de-energizing tie can severely limit the learning and coordination between the two groups. This is especially the case if there are no energizing ties to 
counteract the de-energizing tie and provide alternative opportunities for sharing information.

<Insert Figure 2 about here>

The scenarios simplify what occurs in informal networks within organizations, but help illustrate the range of issues that de-energizing ties often produce. If an individual has one de-energizing tie and 20 energizing ties the effect is different than if half of a person's ties are de-energizing. Remember though: the effect of one negative tie is $4-7$ times greater than the effect of a positive tie. Also, as we noted a de-energizing tie to one's boss or one that crosses the boundary between two teams or departments can have an extraordinary impact.

\section{What Can De-energizing Ties Do to Individuals, Teams and Departments?}

Reduced psychological wellbeing, thriving, and performance Conflict-or negative reactions from colleagues take a toll on people emotionally. We find that de-energizing ties decrease employee thriving, i.e. the joint experience of vitality (feeling energized and alive) and learning (feeling that one is continually improving and getting better at one's work). Whereas positive relationships spur positive feelings and energy to participate and contribute to others and the organization, negative relationships reduce a sense of belonging. In a survey of 135 people in the HR division of a large diverse 
international manufacturing firm (with locations in over 30 countries), we found that the 10 percent of employees who indicated having the most de-energizing interactions reported a thriving score that was 30 percent less than their colleagues. Like uncivil relationships, which pull people off track emotionally and cognitively, de-energizing ties operate the same way. They lead people to narrow their attention. Instead of focusing on how to accomplish their task goals, employees' cognitive resources are likely to be spent on analyzing their de-energizing relationship and how best to navigate (often around) the person.

Having workplace relationships with people to whom one is not emotionally close increases stress. When deciding with whom to engage or seek out information, feelings of negative affect toward the person weigh more heavily than their competence. By not seeking out positive ties, employees limit their access to instrumental knowledge and resources. To the extent that coworkers withhold resources or avoid other group members, performance suffers for them and for their colleagues.

\section{Blocked opportunities}

In knowledge-based organizations (e.g., Deloitte, Google, CIA) who you know is often said to be the key to successfully accessing information necessary to complete tasks. However, it is not only who you know, but also whether or not they will 
share the information with you. De-energizing ties encourage people to separate from key others in the workplace (in particular the de-energizer, but can extend to others, too). Deenergizing ties are blocked opportunities- especially in the short-term. Research by Ron Burt indicates that having ties to people who themselves are not connected, increases the opportunity of receiving non-redundant information. In his seminal work, there is an implicit notion that the ties are positive. If the ties are negative then the non-redundant information is less likely to be received and the individual will have missed a potentially important opportunity. The issue of blocked opportunities goes beyond information; it can also have an effect on an individual's access to resources and promotion opportunities. In our study of 439 management consultants, the detrimental effect of having a deenergizing tie to one's boss is evident: those whose performance was evaluated as only partially meeting expectations were four times more likely to have a de-energizing connection to their supervisor than those who were evaluated as either meeting or exceeding expectations.

In a study of executives at a different consulting firm, we saw how de-energizing ties, particularly those across both faceto-face and virtual teams, were associated with people being overloaded at work and being unsure of their exact role in the 
organization. Executives whose purpose was to coordinate across account teams tended to experience slightly higher role ambiguity and overload than those that only coordinated within account teams. However, when these cross group ties (primarily those to other executives) were de-energizing, their role ambiguity doubled and their role overload tripled. This resulted in an increase in stress and a tendency to avoid interacting with certain individuals-which ultimately reduced performance. By blocking opportunities and harming performance, de-energizing relationships not only take an emotional toll, but they are also a threat to one's career development and financial well-being.

Turnover consequences of de-energizing ties

De-energizing relationships, whether experienced

personally, or within one's workgroup, provoke a sense of unhappiness and dissatisfaction with colleagues and with one's job, reduce motivation, and increase turnover intentions. For example, in one engineering firm, those that perceived more people as being de-energizing were twice as likely to voluntarily leave the organization. In addition, people who chose to voluntarily exit reported that they received 30 percent less positive affect from their colleagues, though the most damaging de-energizing ties are those with the boss. What's more, we find that it's the organization's top talent who are most likely to exit. High performers with an above average 
number of de-energizing ties were 13 times more likely to leave than low and average performers with the equivalent number of de-energizing ties.

Turnover is a large issue for most organizations as the loss of skilled employees affects productivity and overall performance. There is also then a need to hire and train new employees. Even for the lowest minimum wage positions, the Society for Human Resources Management estimates turnover costs at $\$ 3,500$ per employee. In general, they estimate that departures of lower level employees cost organizations 30-50 percent of employees' annual salaries. For middle level employees, the cost of exit rises to an estimated 150 percent of each departing employee's yearly salary. For high-level employees, the figure can top 400 percent of annual salary. Wayne Cascio and John Boudreau note that Merck estimates turnover costs to be 1.5 to 2.5 times the exiting employees' annual salaries, with Ernst and Young estimating 1.5 times for even an inexperienced auditors' exit.

Beyond the mere financial costs though, we find that the more talented, high-performing employees are far more likely to exit organizations because of de-energizing relationships. This is even more likely when a high performer has a de-energizing relationship with their boss. Jeff Pfeffer points out that the retention of talent is the basis of competitive advantage in 
many industries. In a recent study of 200 firms across 40 industries over 10 years, Joyce and slocum show that this is the case-particularly when talent management is aligned with strategic objectives. Specifically, promoting a culture of empowerment, information sharing and trust helps retain top talent. An article in Fortune by Geoffrey Colvin shows that talent is a growing issue: one poll of nearly 1,000 HR professionals revealed that retention and hiring was their top concern, while another survey showed that 77 percent of companies believe that they don't have enough successors for their senior managers. Organizations that ignore de-energizing relationships and their culture will lose as top talent becomes scarcer.

Losses stemming from de-energizing relationships may not be obvious though, as effects and costs may not be felt for many months. Withdrawal from an organization often takes place over time. This makes spotting and attributing de-energizing relationships as the spark or accelerant that leads to turnover more difficult, particularly if these relationships are with a boss, or someone in another work group. This time lag erases the links between de-energizing relationships as cause and departure as effect. It's also likely that organizations do not receive information that de-energizing relationships are what drove people to exit the organization. As we've found with uncivil 
relationships, people almost never report that as the reason for departure.

\section{Contagion effect}

As discussed earlier and shown in Figures 1 and 2, networks are not just about the relationship between two individuals, but also the relationship between one person and their entire network as well as the overall structure of the informal network. Whether in departments or teams, de-energizing ties are contagious and can inhibit people's thinking and behaviors. Research we've conducted with Amir Erez demonstrates how witnessing incivility pulls people off track. Whether people see or hear about a de-energizing tie, it affects them emotionally, disrupts their focus, and leads to decreased performance, creativity, and helpfulness.

Then there's the more explicit reach of de-energizing ties. An individual that has experienced a de-energizing interaction seeks out a colleague, friend, or family member in order to "blow off some steam." While this may bring relief to the individual, it often has a negative effect for the friend or colleague. Not only do they lose time and focus, but they may also become emotionally involved in the issue and not have a clear head to carry on with their own work after the interaction. Some groups burn up work time discussing deenergizing ties or behaviors. 
Even after the initial emotional impact of a de-energizing interaction dissipates, people often lose time and focus while members attempt to support their friend or colleague who may feel wronged. Others spend work time strategizing about how to help their colleague or protect themselves should further incidents occur. We've seen this happen when nurses, residents, and administrators rally around a nurse who has a negative tie with a de-energizing doctor. They may avoid or try to make life difficult for the doctor. In cases like these the de-energizing relationship between two people can diffuse to other relationships that were previously energizing even though the two people in question had never previously had a de-energizing interaction. The efforts to avoid people sap time and productivity from the organization. All too often they occur under the radar.

\section{De-energizing ties lead to dysfunctional teams}

While de-energizing ties can severely inhibit an individual's ability to complete tasks within an organization, a similar effect can occur at the team level. A study of MBA teams found that the higher the number of adversarial relationships within teams, the lower team interaction, team satisfaction, and workload sharing. In one manufacturing firm we found that, on average, each additional de-energizing tie led to a two percent decrease in team cohesion. While energizing ties help to offset 
this effect, five energizing ties were needed to counteract the influence of one de-energizing tie. Interviews with team members revealed that teams were not working well together as members often looked for ways to avoid their teammates. We've found that sometimes just one de-energizing tie within a team reduces their ability to function together. One rotten apple can spoil the barrel.

Even when someone isn't a bad apple per se, their deenergizing effect on the team can be potent. In a recent study of the re-organization of an IT firm, it came to our attention that one individual, Bob, was transferred from one team to another to improve the productivity of the firm. While the intentions behind the move were commendable, Bob went from being viewed as extremely positive, with 85 percent of people who interacted with him indicating an energizing relationship, to being viewed by over half the people he worked with as being a de-energizer within the workplace. Many of his colleagues refused to interact with him. Performance decreased in Bob's new team by 22 percent. Soon after this evaluation Bob left the firm. A subsequent appraisal of the team's performance showed a 15 percent improvement compared to the point prior to Bob's transfer.

Reduced boundary spanning 
As illustrated in Figure 2 when ties between teams or departments are de-energizing, blocked opportunities can affect the whole team or department. Vital information will not be transmitted and can increase the number of silos within an organization. Each team can develop negative perceptions of the other which may lead to increased conflict and can reduce the likelihood of future positive ties developing between the two teams. Lastly, it can result in teams being isolated from the rest of the organization.

One academic department we know has developed such a bad reputation through a series of de-energizing interactions that it creates problems for new members attempting to interact across the university. A recently promoted associate professor told us he will not mention his departmental affiliation on college and university level committees because it reduces his credibility. A junior faculty member tells us of similar

circumstances. As a result of past interactions his departments' reputation for negativity has created a situation where new colleagues face difficulties interacting at the university level and with other departments.

\section{MANAGING DE-ENERGIZING TIES IN ORGANIZATIONS}

De-energizing ties outside of a work setting often fade as individuals are able to avoid regular interaction with each other. In a work setting this is not always possible. It may be 
difficult to sever de-energizing relationships in organizations because they are often a required part of the work or are part of the reporting structure. As evident in our examples earlier, de-energizing ties in organizations must be managed. Ignoring them may be extremely costly to individuals and organizations.

\section{What Can Managers Do About De-energizing Ties?}

When considering how to manage de-energizing ties, managers should consider the three aspects that make up the informal

social network: the relationship between any pair of people, the number of ties that a particular individual has, and the overall structure of the network. To make effective decisions it is crucial that managers identify early any issues pertaining to de-energizing ties. While it is often possible to detect a deenergizing relationship between two people either through direct observation or by direct or indirect communication, it is much more challenging to detect the broader issues of de-energizing networks. This might be seen indirectly through the performance or organizational commitment of individuals or groups. However, it is not always easy to connect the cause with the consequence. Organizational network analysis is one tool which can help to bring these underlying issues to the forefront. We use short 10 minute surveys to ascertain the positive or negative health of groups of employees. While our focus is generally on groups of 50-250 people, a similar methodology can be applied to much 
larger groups of several thousand people within an organization. We have employees evaluate their positive and negative relationships with others based on a couple of simple questions and then the data are amalgamated to create network maps and quantitative network measures such as the number of ties an individual has. The data allow us to evaluate individual relationships, the number of positive and negative ties individuals have, and the overall structure of the informal social network within an organization.

\section{Managing conflict between two individuals}

If there is an obvious conflict situation or de-energizing tie between a particular pair of employees, a manager can attempt to resolve the situation using existing conflict resolution techniques such as sitting down and trying to work through the issue. If there are more deeply seeded issues, a manager might bring in a coach for one or both individuals. This is particularly helpful if you want to bring about behavioral changes. A coach may provide a more unbiased source that can solicit data from others on potential key issues, provide instruction and recommendations for change, and work to repair their de-energizing ties. In our experience, internal and external coaches have served invaluable roles in transforming existing de-energizing ties, and minimizing future ones. 
Alternatively, a manager might minimize the need for the two individuals to interact by moving one to a different role or team, or even firing one of the individuals. We strongly caution against moving a habitual de-energizer, though. Too often, the effects of the de-energizer can spread and make the situation worse. In extreme cases, we've seen departments that no longer accept internal candidates for positions because they've been burned by receiving a few too many de-energizers.

\section{Managing individuals and their de-energizing networks}

If the issue is of a more systemic nature where an

individual has multiple de-energizing ties, then conflict

management techniques are unlikely to be effective. Instead, it is important to understand if a person is primarily the source or the receiver of the de-energizing relationships. We've found that stress, more so than individual personality is the root of de-energizing behavior. Work related sources of stress such as not possessing the right skills, experience or abilities for a particular role can be addressed with training. Coaches may also provide some help. Non-work stress can be resolved with counseling or even enforced time away from the workplace can be beneficial.

Oftentimes people are not necessarily aware of the impression they give to others. If you feel that people are lacking in self-awareness, 360 feedback can help. Because 
feedback is anonymous people - particularly those lower in status - may be willing to provide candid feedback about actions and behaviors that are at the root of de-energizing ties. We're amazed at how many de-energizers are surprised to learn how they are really perceived. While it is not an easy task to break this type of news, providing this feedback can have very important long-term positive benefits if the de-energizer is motivated to change.

Of course if all else, then firing an individual is an important option to consider. Top law firms, hospitals, and many businesses we've worked with agree that it simply isn't worth keeping a habitual de-energizer. The toll they take on the organization is too costly.

If an individual is on the receiving end of numerous deenergizing relationships managers can help by reassigning them to new work groups or teams. Assigning a formal mentor may help assist the individual in navigating energizing and de-energizing work ties within an organization.

\section{Managing de-energizing network structures}

Sometimes the results of an organizational network analysis can reveal larger issues. Informal networks in organizations tend to consist of groups of highly connected people with only a small number of ties connecting the hubs together. In the language of network analysis this is known as the small world 
phenomenon. There are two important issues that this type of network structure creates for managers. First, if the connections between the different network hubs consist of deenergizing ties then there will be little interaction between the groups. For example, we found that the only tie between one unit of an oil and gas organization in Africa and their sister unit in Europe was de-energizing. Despite these two groups having much knowledge that could be mutually beneficial, there was little exchange of ideas due to the negative nature of the single boundary spanning relationship. The organizational network analysis that we conducted helped to bring the issue to light and led the manager in charge to promote greater interaction between others in the two units.

The second issue that small world network structures bring to light is related to the highly connected hubs. When these hubs are made up of energizing connections then the overall performance of the group, unit or department that comprises the hub is, all things equal, going to be higher than when a hub includes de-energizing relationships. Tackling network hubs comprised of de-energizing ties is a more difficult issue for managers to tackle than the others we have discussed above. The obvious solution is to disband whatever work the de-energizing hub is involved in or to reassign the work and the people involved in it to other parts of the organization. The risk in 
doing this, of course, is that instead of having a somewhat self-contained informal network of de-energizing ties, negativity may spread throughout other parts of the organization. We find that a practical alternative to disbanding the group is to bring in some new positive influences.

In an IT consulting firm, we observed this exact phenomenon. One team was tasked with an important project to migrate the existing e-mail system to a new one. The project languished for almost twelve months, not getting past the planning phase. Then the team leaders and a few other core team players were changed to jump-start progress. Under the new staffing arrangements the project was completed in six months. In the original core team, 57 percent of the network ties to the leaders were viewed as lacking energy at best and being deenergizing at worst. In comparison only 13 percent of the connections to the new core leadership team were viewed as deenergizing or neutral. An even starker contrast between these teams was the energy scores of the sponsor and project manager. Over 70 percent of the original incumbent's ties were perceived as being either de-energizing or neutral. Whereas, the figures for the replacement sponsor and project manager were less than 25 percent. By just changing a few team members, not only did morale increase, but also efficiency and performance. The end 
result was the successful completion of the project as well as an overall increase in sales and customer satisfaction.

\section{Managing recruitment, promotion and staffing}

Ideally, organizations would only hire people who were likely to energize others. Without a crystal ball, understanding how an individual will develop their relational network within an organization is very difficult to judge. We have found that team interviews are a great means to better ensure that potential employees are likely to build positive relationships. Several organizations such as Amazon, Google, Rhapsody, and Whole Foods are using team interviews to weed out de-energizers. Teams shoot for consensus on whether the person would be a good fit. This practice has a second benefit. Whereas new employees often feel isolated and fail to get integrated quickly, losing out on valuable learning, team interviews help to promote richer networks for new employees from their first day with a new organization.

We also recommend thorough background checks, with an eye for de-energizing relationships. Patterns are difficult to hide. The key is to track down good sources. In our experience, you may get better information about candidates' de-energizing trail from peers or subordinates.

When it comes to internal promotions or staffing, managers and Human Resource departments, are on much firmer ground, 
especially if they collected organizational network data, 360 feedback or other similar types of information from interviews. While research has shown that any one person's perceptions about the networks of others is notoriously inaccurate, using methods such as organizational network analysis is a good way of getting a birds-eye view of the informal networks of employees. In tandem with interviews, this information can be used to make better decisions about which individuals will be a good fit with regard to upcoming promotion and staffing decisions.

\section{What Can Individuals Do About De-energizing Ties? Work around them}

The informal network is very flexible if you know how to use it. While it is difficult to work around one's boss it is usually possible to find a different person to go to for information on a topic. Mentors can be invaluable sources of advice with regard to how to make the informal organizational network work for you. To manage your own network it is important to sit down and think about what information and resources you

need to do your job. Then consider where you get these from and whether you consider the people to be energizing or deenergizing ties. A simple inventory of needs and relationships will quickly highlight the weak part of a person's network-where the de-energizing ties are, or where (positive) ties are 
absent. It is then important to consider who would be a good option to build a new tie with. If you don't know, then ask people in your network to help you plug the gaps and overcome the need to rely on de-energizing ties. Long term, de-energizing relationships take their toll, so being mindful and choosing energizing people to work with (if you're so lucky), is well worth it.

\section{Back Off}

In some cases you have no option but to work with someone you consider a de-energizing tie. This may be your boss, someone in your department, or on the same team. If you can't escape the person, we suggest limiting your interaction, particularly in person. We've learned of several helpful hints including minimizing or scheduling shorter meetings, communicating via email or phone rather than face-to-face, staying off of teams or committees that include the de-energizer, working different shifts or in different locations than the de-energizer, working from home, and working through the de-energizer's assistant or subordinates. You might also consider backing off of social events and other extra workplace functions if you notice the negative effect it's having on you. While it may reduce opportunities to forge more positive ties, if it's the difference between a spike in stress, or ultimately leaving an organization, it may be worth making these adjustments. 


\section{Try to change or motivate the de-energizers}

It's no easy task to try to address a de-energizing

relationship with the other party. But there are some approaches that work better than others. Reach out to the person; schedule a meeting to discuss a common project. Focus on what you want, but think about mutual wins. The goal is to focus on interests and build rapport. Positive emotions are contagious, so when you have this conversation, be mindful of not only your words, but your non-verbals and tone. Communication studies show that the actual words you use carry far less meaning than the way they're delivered. Seek information about what you might do to improve the relationship. Focus your requests on specifics based on how they'll make you both feel.

\section{Repel them}

The informal organization does not just consist of individuals acting alone. It is made up of coalitions that form and reform over time. A person who acts alone, especially someone that has little formal power, may find it difficult to persuade a manager to shake up a team or work process that is being effected by de-energizing ties. However, a concerted effort by a small coalition of people might well sway a manger's opinion. We've seen this work effectively when a group of nurses and residents took a concern to a hospital chief to raise 
awareness about the effect of a habitual de-energizer. The key is to raise awareness.

\section{Build up your personal resources}

We've found that by building your personal resources up, you're more immune to de-energizing relationships. A crucial resource is one's sense of thriving, i.e. the joint experience of feeling alive and of continuous learning in the workplace. People who feel more vital and more positive about their sense of self-development have greater resources to mitigate a wave of negativity from a colleague. We have found that for people who have a higher sense of thriving a de-energizing interaction with a teammate is likely to take less of a toll or to pull an individual off track from their positive momentum. Those who enjoy a thriving state are likely to regroup quicker as they have other positives to focus on. Whereas a de-energizing relationship may sink someone struggling with their sense of well-being, an individual high in thriving has a buoy to better withstand the impact.

While employees may not have a choice about working with a de-energizing boss or teammate, they can build up their immunity to the effects by focusing on their vitality and learning. People should focus on establishing ties and working with people who energize them. They might also look for meaningful work that fulfils them, and contributes to their self-development. 
Employees should think about scheduling daily activities in ways that are conducive to balancing resource requirements throughout the day. Energy management techniques, detailed by Tony Schwartz and Jim Loehr, are an effective means of bolstering oneself against the negative effects of de-energizing ties. A stronger, thriving self will help ward off the toll of de-energizers.

\section{Exit the organization}

If all attempts to create a energizing network fail then the final option for an employee is obviously to leave the organization. This can be a beneficial decision depending on the circumstances. De-energizing relationships take a tremendous toll on people. Stress, burnout and negative health consequences are common, particularly over time if you're dealing with difficult de-energizing relationships. Exit may be a more likely option for those with lower tenure, however. Those with longer tenure have more invested in an organization, but they often also have the experience and an established network of positive ties that enables them to better avoid de-energizing network ties.

\section{CONCLUSION}

In conclusion, de-energizing ties can have a detrimental effect on individuals, other employees, and teams within organizations. At the individual level de-energizing relationships can result in blocked opportunities, decreased 
motivation, and even organizational isolation. The consequences include decreased levels of thriving, lower performance, and increased likelihood of exit. The effects on others are very similar. Countless co-workers often get sucked into these negative situations. At the team level de-energizing ties can cause more conflict, lower team cohesion and trust, and decrease boundary spanning activity. The result is less access to critical information, a decrease in the ability to solve problems, and overall lower team performance. De-energizing ties are not insurmountable, though. Managerial actions such as conflict resolution, training and mentoring, as well as staffing changes can change the dynamics of informal organizational networks and minimize the effects of de-energizing ties. Likewise, individual actions such as better awareness and strategic management of one's own network can decrease the effects of de-energizing relationships. 


\section{SELECTED BIBLIOGRAPHY}

For an overview of the positive role of social networks in organizations see R. Cross and A. Parker, The Hidden Power of Social Networks: Understanding How Work Really Gets Done in Organizations, Boston: Harvard Business School Press, 2004. Also, R. Cross, A. Parker, L. Prusak, and S. Borgatti, "Knowing What we Know: Supporting Knowledge Creation and Transfer in Social Networks," Organizational Dynamics, 2001, 30 (2), 100-120; R. Cross, C. Ernst, and B. Pasmore, "A Bridge Too Far? How Boundary Spanning Networks Drive Organizational Change and Effectiveness" Organizational Dynamics, forthcoming.

For selected work on the positive role of energy see R. Cross, W. Baker, and A. Parker, "What Creates Energy in Organizations?," MIT Sloan Management Review, 2003, 44(4), 5156. Also, J. C. Linder, R. Cross, and A. Parker, "All Charged Up," Business Strategy Review, 2006, 17(3), 25-29. For suggestions about effective energy management, see the Power of Full Engagement (Free Press, 2003) by Jim Loehr and Tony Schwartz. For the importance of retaining top talent in organizations see W. F. Joyce and J. W. Slocum, "Top Management Talent, Strategic Capabilities, and Firm Performance, " Organizational Dynamics, 2012, 41, 183-193.

For work on negative ties in organizations see G. Labianca and D. J. 
Brass, "Exploring the Social Ledger: Negative Relationships and Negative Asymmetry in Social Networks in Organizations," Academy of Management Review, 2006, 31(3), 596-614. To learn more about incivility in organizations see The Cost of Bad Behavior: How Incivility Damages Your Business and What You Can Do About It (Penguin: Portfolio, 2009) by C. Pearson and C. Porath.

Andrew Parker is an associate professor at Grenoble Ecole de Management. He has conducted social network analysis research in a wide range of Fortune 500 organizations and government agencies. His research has covered top-level executive teams, functional departments, communities of practice, and recently merged companies. Andrew's research has appeared in sloan Management Review, Organizational Dynamics and California Management Review. He is also the co-author of The Hidden Power of Social Networks and co-editor of Networks in the Knowledge Economy. He received his Ph.D. from Stanford University. (Grenoble Ecole de Management, 12 rue Pierre Sémard, Grenoble 38000, France. Tel.: +3347670 65 95, e-mail: andrew.parker@grenoble-em.com)

Alexandra Gerbasi is an assistant professor at Grenoble Ecole de Management. Her research focuses on how negative emotions and distrust in networks can influence outcomes such as thriving, 
job satisfaction and turnover. In addition, her research addresses how individuals recognize opportunities for collaboration and advancement in their networks. Her research has appeared in Social Psychology Quarterly, Organizational Dynamics, MIS Quarterly Executive, Social Forces, and in several books. Her research has been supported by the National Science Foundation and Agence Nationale de la Recherche. She received her Ph.D. from Stanford University. (Grenoble Ecole de Management, 12 rue Pierre Sémard, Grenoble 38000, France. Tel.: +334568066 14, e-mail: alexandra.gerbasidgrenoble-em.com)

Christine Porath is an associate professor of management at the McDonough School of Business at Georgetown University. Her research focuses on organizational culture and leadership. She is co-author of the book, The Cost of Bad Behavior. Her research has appeared in the Harvard Business Review, Academy of Management Journal, Journal of Applied Psychology, Organizational Behavior and Human Decision Processes, Journal of Consumer Research, Academy of Management Executive, and several other journals and books. She received her Ph.D. from the University of North Carolina at Chapel Hill. (Georgetown University, McDonough School of Business, 37 th and O Streets, Washington, DC 20057, USA. Tel.: +1 202687 3209, e-mail: cp423@georgetown . edu). 
Figure 1 .

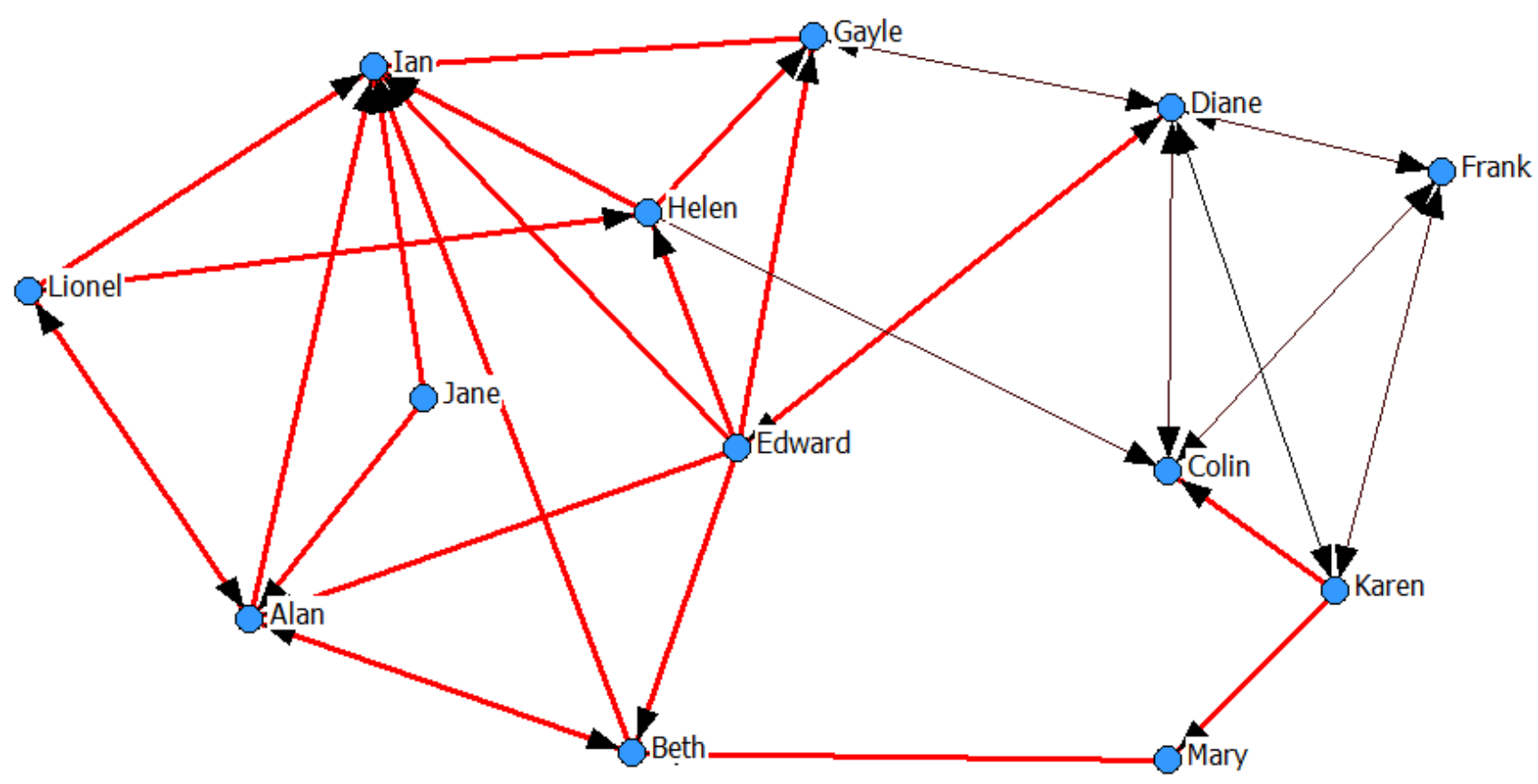

\section{Energizing tie} De-energizing tie

The arrows indicate the direction of the perceived energizing or deenergizing relationship. 
Figure 2 .

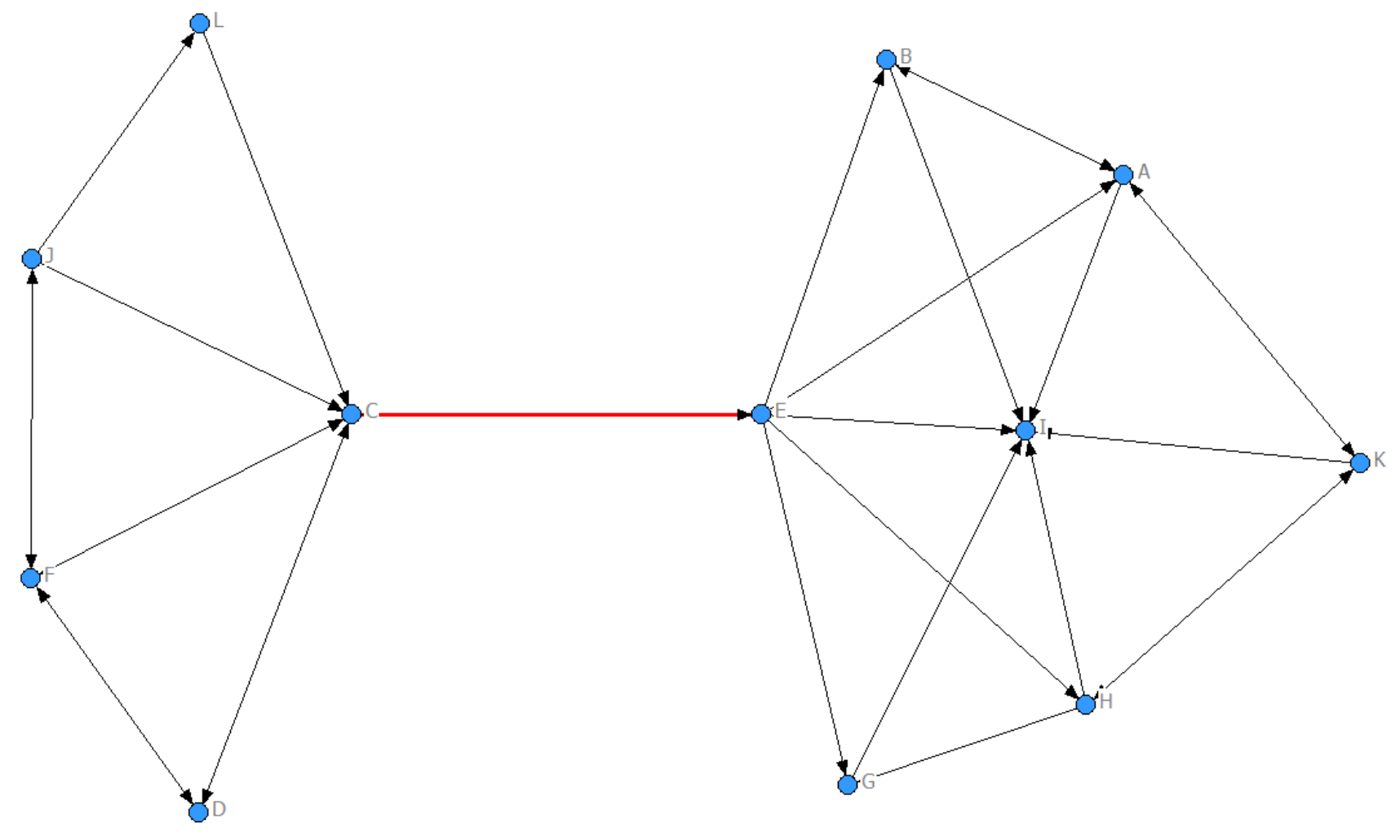

Energizing tie
De-energizing tie 